\title{
AS CONTAS DE VIDRO EM CONTEXTOS ARQUEOLÓGICOS E A IMPORTÂNCIA DAS COLEÇÕES DE ETNOLOGIA AFRICANA E AFRO- BRASILEIRA DO MAE/USP PARA ESTES ESTUDOS
}

\author{
Alessandro Luís Lopes de Lima ${ }^{1}$ \\ Marta Heloísa Leuba Salum²
}

\section{RESUMO}

As contas de vidro estão significativamente presentes nos registros arqueológicos de origem histórica, principalmente em sítios de contato ou relacionados à diáspora africana no Brasil, EUA e Caribe. As contas eram produzidas na Europa e faziam parte de uma rede comercial internacional que distribuía esses artefatos pelas rotas mercantilistas da época, alcançando as colônias americanas. Destacamos o potencial das coleções de etnologia africana do MAE/USP para estas pesquisas, possibilitando análises e correlações através da comparação destas contas arqueológicas com as contas de vidro africanas ou de origens históricas dos candomblés do Brasil e que fazem parte do acervo etnográfico do museu.

PALAVRAS-CHAVE: contas de vidro, contato, diáspora africana, acervos, análise de objeto.

\section{ABSTRACT}

The glass beads are significantly present in the archaeological record of historical origin, especially in contact sites or related to the African Diaspora in Brazil, USA and the Caribbean. The accounts were produced in Europe and were part of an international commercial network that distributed these artifacts by mercantilist routes of the season, reaching the American colonies. We highlight the potential of african ethnology collections of MAE/USP for this research, enabling analysis and correlations by comparing these

1 Mestrando no Programa de Pós-Graduação em Arqueologia do MAE/USP. E-mail: alesslima@usp.br.

$2 \quad$ Prof. ${ }^{\text {a }}$ Dr..$^{\text {a }}$ em Etnologia Africana do MAE/USP. E-mail: lisymhls@usp.br. 
Revista de Arqueologia Pública

archaeological accounts with African beads or historical origins of Candomblé of Brazil and that are part of the ethnographic collection of the museum.

KEYWORDS: glass beads, contact, african diaspora, collections, object analysis.

\section{RESUMEN}

Las perlas de vidrio son significativamente presente en el registro arqueológico de origen histórico, especialmente en los sitios de contacto o relacionados con la diáspora africana en Brasil, EE.UU. y el Caribe. Las perlas se produjeron en Europa y formaban parte de una red comercial internacional que distribuye estos artefactos por rutas mercantilistas, llegando a las colonias americanas. Destacamos el potencial de las colecciones de etnología africanas del MAE/USP para esta investigación, que permite el análisis y las correlaciones mediante la comparación de estas perlas arqueológicos con perlas africanas u orígenes históricos del Candomblé de Brasil y que forman parte de la colección etnográfica del museo.

PALABRAS CLAVE: perlas de vidrio, contacto, diáspora africana, colecciones, análisis del objeto.

\section{ALGUNS ESTUDOS DE ARQUEOLOGIA E ETNOLOGIA A RESPEITO DAS CONTAS}

Nos registros arqueológicos, os cachimbos cerâmicos e as contas de colares são constantes em sítios que tiveram africanos e afro-brasileiros em sua rede de relações sociais, sendo também abundantes na iconografia dos viajantes que vieram ao Brasil durante o século XIX (AGOSTINI et al., 2007, p. 116-117). Muitos tipos de contas estão associados aos africanos escravizados, incluindo-se, entre estas, as retiradas de rosários católicos. Estes colares de contas, normalmente de produção europeia, carregavam significados espirituais e estéticos (SYMANSKI et al., 2007, p. 230).

Os contextos arqueológicos da diáspora africana nas Américas têm sido objeto de pesquisadores no Brasil, Portugal e na América do Norte. Nos EUA um estudo de referência surge no trabalho de Linda France Stine chamado Blue beads as African-American cultural symbols (1996) que fala a respeito da distribuição das contas de vidro em sítios históricos do sul dos EUA, indicando a predominância de contas azuis nos sítios afro-americanos de determinado período do século XIX. Este fenômeno é relacionado não apenas ao uso 


\section{ARTIGO}

\section{Revista de Arqueologia Pública}

dessas contas como adorno, mas também aos aspectos simbólicos associados a sua cor azul. O pesquisador Charles E. Orser Jr. demonstrou em seu artigo The Archaeology of african-american slave religion in the antebellum South (1994) a importância de nós não ignorarmos o tamanho das propriedades coloniais das plantations, já que essa questão está relacionada a atuação e liberdade dos escravos para as práticas religiosas. Em propriedades maiores, nas grandes plantation, a possibilidade de manter elementos de suas tradições religiosas eram maiores do que nas pequenas fazendas, onde o poder de controle era enorme. Esta, porém, é uma hipótese a ser confirmada ainda, já que existem poucos arqueólogos se dedicando ao assunto, segundo Orser Jr. (1994, p. 43). O autor também destaca a dificuldade de se estudar essas práticas nos Estados Unidos, onde eram obrigadas a serem ocultas da sociedade em geral. Os artefatos de religiosidade africana servem como lembranças concretas de que os escravizados africanos trouxeram sua religião e que a adaptaram para uma nova realidade social e política (1994, p. 36). Um destes contextos mortuários ganha importância nesse sentido, mesmo que raros, porque estão normalmente associados aos objetos pessoais do morto. $O$ autor exemplifica a partir de um contexto em Barbados, junto à plantation Newton (séc. XVII), estudados por Handler \& Lange (1978) e onde foram achados os restos de um idoso descendente de africanos, enterrado com vários objetos comuns ao lugar. Entre estes achados braceletes de cobre, anel de metal branco, uma faca de metal e o que Orser Jr. destacou como sendo os mais interessantes, um cachimbo de barro cozido e um colar de contas elaborado. O colar continha 7 cauris, 21 dentes caninos e 40 contas de vidro de vários tamanhos e cores, vértebras perfuradas de um grande peixe e uma pérola cornalina (1994). Essas informações levaram esse indivíduo a ser identificado como um médico curandeiro, onde o cachimbo e o colar o associam à religiosidade africana. Em outro exemplo citado por Orser Jr., agora escavado e publicado por ele mesmo em 1986, foi um enterramento com influências cristãs, encontrado junto ao primeiro cemitério oficial de Nova Orleans, do início do século XVIII. Dos 32 enterramentos escavados, apenas um continha objetos religiosos. Estes objetos eram um rosário com 63 contas pretas de madeira e duas medalhas de prata, sendo uma brasonada com São Cristóvão e outra com a Nossa Senhora e uma criança. As mutilações nos dentes incisivos era uma realidade nesse enterramento, por isso sua associação à África segundo Orser Jr., citando estudos de Handler (1982) e Stewart \& Groone (1968). O rosário indicaria a conversão em algum momento de sua vida, não podendo saber se fora feita na África ou nas Américas. A diferença entre os enterros citados por Orser Jr. indicaria para o autor a ampla diversidade dos povos africanos que vieram para as Américas. A 


\section{ARTIGO}

Revista de Arqueologia Pública

busca por objetos africanos religiosos é o cerne da arqueologia da religião dos escravizados (1994, p. 38).

No artigo As contas abordo da fragata de Santo Antônio de Taná (1697): Um exemplo de intercâmbio no mundo global, a pesquisadora Andreia Martins Torres (2013) parte das escavações de um navio para problematizar os significados das contas de vidro no contexto comercial entre a Índia e a África. Mombaça, onde a fragata foi encontrada, era o eixo principal de ligação entre a Europa, África e a Ásia. As contas seriam um elemento privilegiado de troca desde o início do comércio entre a África e a Europa, em um sistema abastecido pelos comerciantes muçulmanos. As contas de vidro como mercadoria alcançaram escala global, integrando parte de um circuito que ligava os entrepostos do Oceano Índico aos entrepostos do Pacífico, e estes com cidades coloniais nas Américas chegando ao Oceano Atlântico. Essa realidade mercantilista levou ao aparecimento de contas chinesas no vice-reino da Nova Espanha (TORRES, 2013, p. 188). Partindo da conjuntura portuguesa através da fragata de Santo Antônio de Taná, que realizou várias viagens à Europa e ao Brasil, o reflexo do império português estava colocado na amostra das contas encontradas na fragata, fossem elas orgânicas ou de vidro. Estes circuitos comerciais em que a península portuguesa estava inserida acabaram por difundir as contas pelos continentes. Em seu artigo, Andreia Torres classifica e separa as contas escavadas entre as naturais (líticas, conchas, azeviche, madeira, sementes) e as contas de vidro. Eram produtos da manufatura de vários continentes, testemunhando a circulação de pessoas e bens de uso comercial por todo o mundo naquele período.

A obra de Horace Beck, chamada Classification and Nomenclature of Beads and Pendants (1976), formalizou um sistema aplicável às contas de todo o mundo, informandonos que para uma descrição total desse tipo de objeto é necessário averiguar o estado das suas formas, suas perfurações, coloração, material e decoração (BECK et al., 1976, p. 2). É uma obra de referência e que nos serve para futuros levantamentos a serem realizados nos acervos do MAE/USP.

No Brasil, Luís Cláudio Symanski (2007) faz um levantamento de trabalhos em contextos arqueológicos afro-brasileiros em que menciona o trabalho de Marcos Souza, intitulado Uma outra escravidão: a paisagem social do Engenho de São Joaquim, Goiás, publicado na revista Vestígios, revista latino-americana de arqueologia histórica. Lá se destaca uma amostra significativa da vida material afro-brasileira representada pelo que foi escavado: louças europeias baratas e garrafas, pulseiras e brincos, e contas de vidro, mas não se menciona claramente se esses achados teriam uma relação direta com os dados \begin{tabular}{|l|l|l|l|l|l|l|}
\hline (C) Rev. Arqueologia Pública & Campinas, SP & v.11 & n.1 & p. 6 & Julho/2017 & ISSN 2237-8294
\end{tabular} 


\section{ARTIGO}

\section{Revista de Arqueologia Pública}

socioculturais conhecidos como característicos e específicos das comunidades afrobrasileiras.

Dois projetos mais recentes de pesquisadores brasileiros consolidados na pesquisa arqueológica sobre diáspora africana, sendo um deles do próprio Symanski, relatam contas entre os achados de contextos afro-brasileiros. É o caso do Projeto Café com açúcar: arqueologia da escravidão em uma perspectiva comparativa no sudeste rural escravista séc. XVIII e XIX, de 2012, realizado no Colégio dos Jesuítas de Campo dos Goytacazes, Rio de Janeiro, onde Luís Cláudio Symanski identificou uma área de deposição de refugo que remonta à primeira metade do século XIX, em um antigo conjunto de senzalas. Nas escavações foram resgatadas grande quantidade de ossos de mamíferos domésticos e silvestres, conchas de mariscos, fragmentos cerâmicos, louças portuguesas do século XVIII e inglesa do século XIX, ornamentos de cobre martelado, cachimbos de cerâmica e contas de vidro (SYMANSKI et al., 2007, p.188).

Outro projeto, cujas pesquisas encontram-se ainda em andamento, é o de Tânia Andrade de Lima no antigo porto de entrada de escravos do Rio de Janeiro, entre 1811 e 1831 - antes chamado Cais do Valongo. São pesquisas que estão sendo realizadas desde 2011 nas obras de revitalização da área portuária do Rio de Janeiro, o projeto do Porto Maravilha para as Olimpíadas de 2016, pelas quais estavam sendo identificadas milhares de contas de vidro, anéis de fibra vegetal torcida e de metal, cachimbos cerâmicos, brincos, pulseiras e figas de cobre, madeira e ossos, moedas, cristais de quartzo, ambares, búzios (ou cauris), representações do cosmograma bacongo em vasilhames cerâmicos, em cabos de colher de metal etc. (LIMA, 2013, p.184).

Temos visto, porém, que nestes e em outros relatórios a que já tivemos acesso através das publicações, embora as contas sejam constantes como achados em escavações arqueológicas no Brasil, e em particular nos sítios com componentes de origem negro-africana, são raros os que nelas se detêm, como se dá em relação aos cachimbos cerâmicos ou a outros elementos associados à cultura material afro-brasileira ou de origem africana.

Nos três últimos anais dos congressos da Sociedade de Arqueologia Brasileira (SAB) há apenas um trabalho intitulado Arqueologia do Quintal Beneditino: Os Escravos da Religião ${ }^{3}$, associado ao projeto de salvamento arqueológico realizado na Rua São Bento, no

3 XVII Congresso da SAB. Autoras: Jeanne Cordeiro de Oliveira e Márcia Barbosa da Costa Guimarães.

\begin{tabular}{l|l|l} 
v.11 & n.1 & p. 7
\end{tabular}




\section{ARTIGO}

\section{Revista de Arqueologia Pública}

centro histórico do Rio de Janeiro, coordenado por Márcia Barbosa da Costa Guimarães que toma contas como objeto de estudo. Tendo-se como "diaspórica" a população que viveu em parte deste sítio desde o século XVI, as autoras do trabalho selecionaram entre o material achado no local alguns objetos religiosos como contas de leguidibá e de vidro "para compreender as práticas gentílicas e modos de viver frente aos poderes no espaço religioso Beneditino" (OLIVEIRA \& GUIMARAES, 2015). É um trabalho ainda inicial e sem resultados a que tivéssemos acesso.

Áurea Conceição Pereira Tavares desenvolveu uma dissertação de mestrado junto à UFPE intitulada Vestígios materiais nos enterramentos na antiga Sé de Salvador: Posturas das instituições religiosas africanas frente à igreja católica em Salvador no período escravagista (TAVARES, A., 2006), orientada pelo Prof. Dr. Carlos Alberto Etchervarne. Os 55 sepultamentos encontrados nessa pesquisa levaram Áurea Tavares à hipótese de tratarse de um contexto relativo a práticas religiosas afro-brasileiras. Nesses sepultamentos foi identificada, junto aos indivíduos, uma significativa quantidade de contas de origem africana feitas de vidro e marfim, assim como de cauris. As análises de estratigrafia e de fontes documentais indicam uma cronologia entre séculos XVIII e XIX. Para a sua interpretação, a autora valeu-se de analogias entre os tipos de matérias-primas, formas e combinações das cores ali identificadas com as utilizadas pelos candomblés contemporâneos.

De fato, inúmeros trabalhos de etnologia realizados no Brasil demonstram que, ritualmente nos candomblés, são usadas contas de vidro, como miçangas em colares, cintos e outros adereços da indumentária, como no mobiliário cultural e nos espaços sagrados. Pesquisas associadas a este mesmo cemitério da antiga catedral da Sé de Salvador, realizadas por Andersen Líryo da Silva, mas dentro do campo da Bioarqueologia (SILVA, A., 2011), mostra-nos que alguns daqueles 55 esqueletos possuíam mutilação dentária intencional, nos dentes incisivos principalmente, levando à hipótese de que, datados do século XIX, poderiam ser originários da Costa da Mina. Apesar desta pesquisa ainda exigir uma investigação complexa de outras fontes dentro de um projeto mais amplo e interdisciplinar, seus resultados são bastante significativos: a Costa da Mina é origem de africanos da África ocidental trazidos como escravos para o Brasil, compreende o litoral dos territórios do antigo Daomé, atual Benin, e Nigéria, onde vivia grande parte dos povos lorubá, que constituíram a maioria das últimas levas de africanos antes da abolição do tráfico e que aportavam na Bahia nesse período. Os principais candomblés baianos, conhecidos a partir da metade do século XIX, são majoritariamente de cultura iorubana e de povos vizinhos dessa região da África (ver, entre outros, VERGER, 2012). Raul Lody em 


\section{ARTIGO}

\section{Revista de Arqueologia Pública}

Joias do Axé: fios-de-contas e outros adornos do corpo: a joalheria afro-brasileira (2001) realizou um trabalho sobre o uso das contas entre os frequentadores dos candomblés nagôs da Bahia, revelando-nos, assim, a produção, uso e a circulação das contas entre o povo de santo dos candomblés nagô. $O$ fio de contas seria um emblema social e religioso marcado pelo compromisso ético e cultural entre o homem e o seu santo, situando o indivíduo na comunidade do terreiro e obedecendo o critério para compor os textos visuais dos fios de contas (LODY, 2001). Apesar de ser um trabalho descritivo e etnográfico, o que Lody descreve sobre a morte pode nos auxiliar a elaborar vínculos possíveis de relação entre achados arqueológicos em sepultamentos com o contexto cultural. Após o falecimento do dono do colar de contas, estas serão utilizadas em oferendas fúnebres, e as mais valiosas, conforme valor material, simbólico e o vínculo com o axé do terreiro, serão distribuídas entre pessoas da comunidade, principalmente entre os usuários mais próximos ao morto. As contas do morto irão compor outros fios de contas, brincos, pendentes e passarão por novos rituais de lavagens, comuns a vida religiosa dos fiéis da religiosidade afro-brasileira. Essa distribuição, redistribuição e reincorporação aos símbolos servem para fortalecer o sentido de unidade e preservação da memória do terreiro, principalmente de seu axé. Aqui, concordando com o que lan Hodder sempre chamou a atenção em sua teoria, fica perceptível o papel dos indivíduos na composição visual e morfológica das contas, já que, literalmente, o indivíduo determina e é determinante na produção da cultura material, não apenas refletindo passivamente a sociedade mas também criando e interagindo com a materialidade, através de suas ações (HODDER et al., 2001, p. 21). As contas estão em multiuso no universo do terreiro, possuindo uso corporal em indumentárias e ferramentas, uso arquitetônico enfeitando barracões, compondo assentamentos. O uso social e religioso deve ser considerado, entre outros (LODY, et al. 2001, p.114).

\section{PESQUISAS RECENTES}

Existem pesquisas arqueológicas recentes envolvendo o estudo de contas, não apenas em senzalas, quilombos ou naufrágios, mas também em candomblés. É o caso da tese de doutorado de Samuel Lira Gordenstein, intitulada De sobrado a terreiro: a construção de um candomblé na Salvador oitocentista (GORDENSTEIN, 2014), também com orientação do Prof. Dr. Carlos Etchevarne, propõe um estudo aprofundado sobre este tipo de achado, voltado à materialidade, aos significados e usos. 


\section{ARTIGO}

\section{Revista de Arqueologia Pública}

Patrícia Carolina Letro de Brito, em 2015, apresentou no Programa de PósGraduação do Mestrado em Arqueologia do Museu Nacional (UFRJ) a dissertação intitulada De conta em conta: rotas atlânticas e comércio no Rio de Janeiro. O caso do Cais do Valongo, desenvolvida sob a orientação de Tânia Andrade Lima. A autora defende a importância dos estudos relacionados às populações escravizadas, já que ajudam na compreensão do cotidiano do africano no Brasil, valorizando dados renegados por muito tempo pelas versões oficiais. Em sua dissertação a respeito das contas de vidro encontradas no Cais do Valongo - cerca de 2.800 artefatos, entre inteiros e semidestruídos -, buscou conhecer as rotas comerciais dessas contas e de outros materiais para o mercado do Rio de Janeiro da época, desde sua manufatura nos centros produtores europeus até a colônia. Ao mesmo tempo, a autora buscou compreender como a população cativa atuou nesse comércio. Seu arcabouço teórico e metodológico foi retirado dos pontos convergentes entre a Arqueologia Histórica, a Arqueologia do Capitalismo e a Arqueologia da Diáspora Africana e possibilitaram ampliar as reflexões a respeito das contas de vidro.

Rosana Najjar é organizadora do livro Arqueologia no Pelourinho (NAJJAR, 2010) que trata da pesquisa arqueológica dentro da $7^{\mathrm{a}}$ Etapa do Projeto Pelourinho, Restauração do Centro Histórico de Salvador/BA, Monumenta/IPHAN, da qual a pesquisadora foi também coordenadora. Nesse sítio, foram coletadas 413 contas que estavam juntas aos enterramentos evidenciados, a presença de contas e de cachimbos inteiros ou em fragmentos ultrapassam duas mil peças; as contas foram recuperadas em depósitos primários e os cachimbos provêm de aterros. Não há, no caso deste sítio, associação interpretativa direta entre esses dois tipos de artefatos. Finalmente, essas contas podem ser classificadas por cor e matéria-prima, sendo 343 brancas, 69 pretas e uma incolor, destacando-se nesta publicação apenas uma conta diferenciada: um pingente de cauri. Algumas dessas contas são consideradas pela autora como provavelmente de rosários, "usados em enterramentos cristãos", e quanto àquelas que fogem ao padrão (as brancas dos rosários), acredita-se que talvez fossem elementos de colar usados "por negros, principalmente africanos, em rituais religiosos" (NAJJAR, 2010, p. 240; ver tb. p. 263-264).

\section{AS COLEÇÕES DO MUSEU DE ARQUEOLOGIA E ETNOLOGIA DA USP}

Têm crescido velozmente os registros de contas e miçangas em contextos arqueológicos, mas foram pouco estudadas em sua grandeza até esse momento, sendo 


\section{ARTIGO}

\section{Revista de Arqueologia Pública}

comuns em sítios arqueológicos de contato. Acreditamos que em breve as contas e miçangas serão cada vez mais descobertas em seu potencial de pesquisas e reconhecidas enquanto "registro arqueológico" de fato.

Há que se considerar a importância que tem sido dada a elas na chamada "Arqueologia da diáspora" e a "Arqueologia da Escravidão", relativas ao Negro no Brasil. E conforme diz Najjar (2010, p. 263) sobre o Projeto Pelourinho, possivelmente a maioria delas teria sido importada, desta forma nos vem à memória o potencial de estudos das contas (adereços ou outros objetos) presentes em coleções como as africanas e afrobrasileiras do MAE, Museu de Arqueologia e Etnologia da USP. As coleções de Etnologia Africana e Afro-brasileiras do acervo do MAE/USP têm sido empenhadas não apenas para ensino e difusão, mas também para a pesquisa etnológica e estudos de história da Arqueologia africana e de perspectivas da Arqueologia pós-colonial. As contas de vidro e de diversos outros materiais que pertencem a essas coleções podem formar um importante núcleo de referência material africana (pela procedência), ou seção deste corpus. Referimonos aqui às peças trazidas da África, mas devemos considerar também as das coleções afro-brasileiras do acervo. Todas as contas ali constantes, isoladas, em fragmentos artefatuais ou aplicadas em objetos de natureza diversa, têm alguma similaridade com as dos sítios de Arqueologia Histórica do Brasil ou das Américas, assim como também com as que ainda se encontram em uso social nos diversos contextos africanos já referidos acima.

Para Gonzales Ruibal, são pertinentes os levantamentos museográficos em coleções antropológicas que guardam em seus acervos artefatos que podem nos passar detalhes sobre usos e contextos sociais, temas de interesse primordial para a abordagem arqueológica (RUIBAL et al., 2003, p. 9-10). Deve-se dizer que a massa vítrea é o material mais presente nas contas observadas nas coleções africanas e afro-brasileiras do MAE/USP (SALUM et al., 2010, p. 70) e indica uma possível prática de reciclagem. Luís Claudio Symanski, em seu artigo intitulado Artefatos reciclados em sítios arqueológicos de Porto Alegre (SYMANSKI, 1996), traz uma abordagem da reciclagem da louça e do vidro em sítios históricos brasileiros do século XIX, bastante centrado pela perspectiva comportamental.

Segundo Marta Heloísa Leuba Salum, pesquisadora do setor de Etnologia Africana do MAE/USP, a coleção africana do Museu de Arqueologia e Etnologia da USP pode ser considerada como uma das mais importantes do Brasil, nos termos de peças de cultura material africana tradicional, concorrendo com apenas outras duas, a coleção Etnográfica 


\section{ARTIGO}

Revista de Arqueologia Pública

Africana do Museu Paraense Emilio Goeldi e a coleção Arte Africana do Museu Nacional de Belas Artes, no Rio de Janeiro.

Com o propósito de resgatar a herança africana e ressaltar sua permanência, o Prof. Dr. Ulpiano Bezerra de Meneses, em 1969, incentivou a formação de uma área dedicada a arte e cultura material africana no antigo Museu de Arte e Arqueologia da USP (SALUM,1993). Suas peças possuem a procedência de doadores como Pierre Verger, Mariano Carneiro da Cunha, Dilma de Melo e Souza, entre outros. Mais da metade dos objetos foram comprados com verba da SAMAE e até o último registro do livro de tomo (1987) o museu contou com mais de mil peças de origem africana. Muitos lotes que deram entrada na coleção vieram da época da estada de Mariano Carneiro da Cunha, na Nigéria, entre os anos de 1974 e 1975, com peças adquiridas no Benin e no Senegal, sendo representativas não apenas dos povos lorubá, mas de toda África Ocidental (Subidem, p.169). A coleção Acervo Sertanejo fez parte no passado do acervo integrado à secção de Etnologia do antigo Museu Paulista, possuindo sua musealização relacionada ao contexto de recrudescimento dos estudos folclóricos nos anos 40 e 50 . Essa coleção recebeu doações de inúmeros folcloristas e entre seus doadores Alceu Maynard Araújo, Frederico Lane e Carlos Borges Schimdt, que além de oferecer peças ao Museu Paulista, escreveram sobre elas na Revista do Museu Paulista (Nova série). A coleção recebeu peças avulsas e outras de antigas coleções, somando-se aos objetos doados acabou por se tornar uma coleção heterogênea (SALUM; CERAVOLO et al., 1993, p.168). Entre as coleções absorvidas, destaca-se a Coleção Etnográfica Fetichista da Bahia (CEFB), de onde vêm inúmeras peças como ferramentas de Orixás, louças, instrumentos musicais como adjás, atabaques, agogôs, além dos fios de contas. Essa coleção é fruto de apreensão pela polícia baiana e foi doada pelo secretário de justiça do estado da Bahia em 1928, segundo o inventário do Museu Paulista. Outra coleção que deu origem ao Acervo Sertanejo do MAE/USP foi a chamada Objetos da Secretaria de Segurança Pública do Estado de São Paulo, onde aparecem cerca de 298 peças apreendidas pelo departamento de Investigações da Secretaria de Segurança Pública e que foi oferecida ao Museu do estado pela Delegacia de Fiscalização de Costumes em 1947 (LAMPARELLI et al., 2014, p. 9). Lamparelli considera que essa coleção hoje é repositória de artefatos de valor Histórico e Etnológico dos descendentes de africanos e de sua cultura material. Rita Amaral, pesquisadora da coleção Sertaneja, a qual chamava confusamente de Registro Sertanejo, diz ter identificado em uma listagem as origens de algumas peças que compunham a coleção. Foram encontradas 187 peças das 252 listas, datadas do princípio do século XX, de cultos afro-brasileiros localizados no interior do estado de São Paulo. Segundo 


\section{ARTIGO}

Revista de Arqueologia Pública

informações contidas nessas listagens, algumas peças teriam sido levadas para o Museu Paulista em 1914, outras em 1938 e 1943, sendo originárias de cultos do interior de São Paulo (Tietê, Pirapora, Araraquara e Jundiaí), doadas pela secretaria de Segurança Pública, aprendidas durante período de repressão ao culto (AMARAL et al., 2000, p.17).

Marianno Carneiro da Cunha, ao se referir aos objetos de adorno e ornamentos pessoais de origem metalúrgica que se encontram na coleção africana do MAE/USP, utilizou o termo "Joia" (CARNEIRO DA CUNHA, 1983). Possuímos a preferência em trabalhar com os conceitos de "contas", principalmente como Raul Lody define: um termo geral para tudo que é feito por enfiamento, com a finalidade de formar um fio de contas, podendo ser um leguidibá para Omulu, uma segi (contas azuis) para Oxanguiã ou um mongoló para lansã, entre vários outros tipos. Um outro termo o qual também utilizamos é o "miçanga", de origem quimbundo e comumente utilizado como sinônimo de contas de vidro, miúda ou o ornamento feito com essas contas, como definido pelo Novo Dicionário Bantu do Brasil (LOPES, 2003).

O MAE/USP, possuindo um acervo africano de grande tradição e importância, oferece-nos a possibilidade de explorar um conjunto de contas africanas, isoladas ou em artefatos, em todo seu potencial. No mesmo sentido, a coleção Acervo Sertanejo merece atenção especial, sendo testemunha da antiguidade dos cultos afro-brasileiros, possui o potencial de gerar paradigmas a partir do qual estudos de cultura material possam vir a se desenvolver, inclusive podendo contribuir com os debates relativos aos processos transformativos, sendo estas pesquisas de importância não apenas para academia mas também para as comunidades e pessoas que carregam as identidades e religiosidades afrobrasileiras (AMARAL, 2002).

Além das referidas coleções de Etnologia Africana e Afro-brasileira, o MAE/USP possui um farto material relacionado às contas a ser levantado em coleções arqueológicas, tal como na Mediterrânea e na Brasileira. Entre o material coletado pela equipe de pesquisadores organizada por José Luiz de Moraes no Sítio Engenho dos Erasmos e depositado no MAE, encontram-se três contas de Chevron ou Rosetta (SJE 2.242; SJE 2.243 e SJE 2.241), relativas ao período de contato e que podem vir a ser comparadas com outras contas de Chevron presentes nas coleções de Etnologia Africana (SALUM, 2011). Nos acervos do MAE/USP, também se encontra a coleção do Sítio Itaguá (Ubatuba-SP), escavado por Dorath Pinto Uchôa e Caio Del Rio Garcia na década de 1970, identificado como de origem Tupi e caracterizado como sítio de contato. Foram encontradas nesse sítio 4 contas de vidro, tubulares e azuis, que os autores as reconheceram como principal \begin{tabular}{|l|l|l|l|l|l|l|}
\hline (C) Rev. Arqueologia Pública & Campinas, SP & v.11 & n.1 & p. 13 & Julho/2017 & ISSN 2237-8294 \\
\hline
\end{tabular} 
elemento de diagnóstico do contato com o europeu (UCHÔA; SCATAMACCHIA; GARCIA, 1984).

Faz-se necessário o esforço de pesquisa sobre estas coleções para o levantamento e cruzamento de dados relativos à tecnologia, produção, consumo e significado das contas e miçangas africanas, afro-brasileiras, europeias e indígenas.

Consideramos, assim, que as contas e miçangas são tão valorosas quanto faianças ou moedas na caracterização de sítios, sendo objetos que apontam para usos variados (muitas contas tiveram papel de troca, daí seu valor de prestígio ou poder) e podem ajudar na identificação de outros vestígios arqueológicos, como na identificação de esqueletos no Pelourinho (NAJJAR, 2010, p. 113).

Concordamos com Camila Agostini ao nos dizer que as contas não tiveram atenção merecida por parte dos arqueólogos brasileiros (AGOSTINI et al., 2007, p.117). A importância de seu estudo está, para além de sua beleza estética, na possibilidade de elucidação de questões relacionadas ao patrimônio do Negro no Brasil e nas Américas e sua preservação, bem como de seu papel na formação e construção da identidade negra no país (cf. SALUM et al., 2010, p 74). 


\section{ARTIGO}

Revista de Arqueologia Pública

\section{REFERÊNCIAS BIBLIOGRÁFICAS}

AGOSTINI, Camila. Resistência cultural e reconstrução de identidades: um olhar sobre a cultura material de escravos do século XIX. Revista de História Regional, v. 3, n. 2, 2007.

AMARAL, Rita. A coleção etnográfica de cultura religiosa afro-brasileira do Museu de Arqueologia e Etnologia da Universidade de São Paulo. Revista do Museu de Arqueologia e Etnologia, n. 10, p. 255-270, 2000.

Notas sobre o processo transformativo da cultura material dos cultos afro-

brasileiros, In: Congresso Virtual, 2002. Disponível em: http://www.equiponaya.com.ar/congreso2002/ponencias/rita_amaral.htm Acesso em $15 / 15 / 2015$.

BECK, Horace C. Classification and nomenclature of beads and pendants. George Shumway Publisher, 1973.

BRITO, Patrícia Carolina Letro; De conta em conta: rotas atlânticas e comércio no Rio de Janeiro. O caso do cais do Valongo. Dissertação de Mestrado, Museu Nacional (UFRJ), Rio de Janeiro, 2015.

CARNEIRO DA CUNHA, Marianno. Arte afro-brasileira. In: ZANINI, Walter (Org.); História Geral da Arte no Brasil. Instituto Walther Moreira Salles, 1983.

DREWAL, Henry John; MASON, J. Beads, Body and Soul: Art and Light in the Yoruba Universe; Los Angeles: UCLA, 1998.

DUBIN, Lois Sherr. The history of beads from $30,000 \mathrm{BC}$ to the present. Harry N. Abrams. Inc., 1987.

GORDENSTEIN, Samuel Lira. De sobrado a terreiro: a construção de um candomblé na Salvador oitocentista. Tese de Doutorado em Antropologia. UFBA, Salvador, 2014.

GORDON, Albert F. The tribal bead: a handbook of African trade beads. New York: Tribal Arts Gallery, 1976.

GUIMARÃES, Márcia Barbosa da Costa; OLIVEIRA, Jeanne Cordeiro; Arqueologia do Quintal Beneditino: os escravos da religião. In: CONGRESSO DA SOCIEDADE DE ARQUEOLOGIA BRASILEIRA, 17., 2013, Aracaju. Resumos. Disponível em: 


\section{ARTIGO}

Revista de Arqueologia Pública

http://www.xviicongresso.sabnet.com.br/download/download?ID DOWNLOAD=173. Acesso em: $22 / 12 / 2015$.

HODDER, lan. Interpretación en Arqueología. Corrientes Actuales. Barcelona: Crítica, 1994.

IPHAN; NAJJAR, Rosana (Coord.) Arqueologia no Pelourinho. Brasilia: Iphan/Programa Monumenta, 2010.

LAMPARELLI, Mário de Campos Andrade. Sonoridade de África e Brasil: Materialidade e diálogo na documentação de peças do acervo do MAE;UUSP; São Paulo: Museu de Arqueologia e Etnologia/USP. 2014.

LIMA, Arqueologia histórica no Brasil: balanço bibliográfico (1960-1991). Anais do Museu Paulista: História e Cultura Material, v. 1, n. 1, p. 225-262, 1993.

Arqueologia como ação sociopolítica: o caso do Cais do Valongo, Rio de Janeiro, século XIX. Vestígios, Revista Latino Americana de Arqueologia Histórica, v. 7, p. 177204, 2013.

LODY, Raul Giovanni da Motta. Jóias de Axé: fios-de-contas e outros adornos do corpo. Rio de Janeiro: Bertrand Brasil, 2001.

LOPES, Nei. Novo dicionário banto do Brasil. Rio de Janeiro: Pallas, 2003.

ORSER, Charles E. The archaeology of African-American slave religion in the antebellum South. Cambridge Archaeological Journal, v. 4, n. 01, p. 33-45, 1994.

RUIBAL, Alfredo González. La experiencia del otro: una introducción a la etnoarqueología. Barcelona: Ediciones Akal, 2003.

SALUM, Marta Heloísa Leuba. CERAVOLO, Suely Moraes. Considerações sobre o perfil da coleção Africana e Afro-brasileira no MAE-USP, Revista do Museu de Arqueologia e Etnologia, São Paulo, n. 3, p.167-185, 1993.

Por mais que sejam belas, que dizem simples contas? In: CONGRESSO DA SOCIEDADE DE ARQUEOLOGIA BRASILEIRA, 15., 2010, Belém. Anais, Belém: SAB, 2011.

SILVA, Andersen Liryo. Saúde bucal dos escravos da Sé de Salvador, Bahia, séc. XIX; Revista de Estudos Americanos, volume 1; n.1; jan-jul. 2011.

\begin{tabular}{|l|l|l|l|l|l|l|}
\hline (C) Rev. Arqueologia Pública & Campinas, SP & v.11 & n.1 & p. 16 & Julho/2017 & ISSN 2237-8294
\end{tabular}




\section{Revista de Arqueologia Pública}

SCATAMACCHIA, Maria Cristina Mineiro; UCHÔA, Dorath Pinto. O contato euro-indígena visto através de sítios arqueológicos do estado de São Paulo. Revista de Arqueologia. Sociedade de Arqueologia Brasileira (SAB). Vol. 7. São Paulo, 1993. p. 153-173.

STINE, Linda France; CABAK, Melaine A.; GROOVER, Mark D. Blues Beads as AfricanAmerican Cultural Symbols. Historical Archaeology, 30 (3), p. 49-75, 1996.

SYMANSKI, Luís Claudio Pereira, A Arqueologia da Diáspora Africana nos Estados Unidos e no Brasil, Afroasia, n. 49, p.159-198, 2014.

OSÓRIO, Sérgio Rovan. Artefatos reciclados em sítios arqueológicos de Porto Alegre. Revista de Arqueologia, n. 9, p. 43-54, 2015.

- O domínio da tática: práticas religiosas de origem africana nos engenhos de Chapada dos Guimarães (MT). Vestígios - Revista Latino-Americana de Arqueologia Histórica, Belo Horizonte, v.1, n. 2, p. 9-36, 2007.

; SOUZA, M. A. O registro arqueológico dos grupos escravos: questões de visibilidade e preservação. Revista do Patrimônio Histórico e Artístico Nacional, v. 33, p. 215-243, 2007.

TAVARES, Aurea Conceição Pereira. Vestígios materiais na antiga Sé de Salvador: postura das instituições religiosas africanas frente à Igreja Católica em Salvador no período escravista. Dissertação de mestrado. Centro de Filosofia e Ciências Humanas da Universidade Federal de Pernambuco. Recife, 2006.

TAVARES, R B; Cemitério dos pretos novos, Rio de Janeiro, século XIX: Uma tentativa de delimitação espacial. Dissertação de mestrado, Universidade Federal do Rio de Janeiro. Rio de Janeiro, 2009.

TORRES, Andreia Martins. As contas a bordo da fragata Sto. António de Taná (1697): um exemplo de intercâmbios num mundo global. História Revista, v. 18, n. 2, p. 8, 2013.

UCHÔA, Dorath Pinto; SCATAMACCHIA, Maria Cristina Mineiro; GARCIA, Caio Del Rio. O Sítio Cerâmico do Itaguá: Um sítio de contacto no litoral do Estado de São Paulo, Brasil. Revista de Arqueologia. Belém. Vol. 2. Número 2. Julho/dezembro de 1984. p. 51-59.

VERGER, Pierre Fatumbi; Notas sobre o culto dos Orixás e Voduns na Bahia de todos os santos, no Brasil, e na antiga costa dos escravos na África; São Paulo: Edusp, 2012. 